Thorax (1964), 19, 338.

\title{
Bronchogenic carcinoma in women
}

\author{
W. J. H A N B U R Y
}

From the Department of Pathology, St. Bartholomew's Hospital, London, E.C.I

The unequal sex incidence of lung cancer, with the decided preponderance of males (Willis, 1960), constitutes one obvious line of enquiry into the aetiology of the disease. Numerous papers on various aspects of bronchogenic carcinoma have included comparisons between male and female cases, but reports of detailed studies of the disease in women have been relatively few. Among the more recent publications are three from the United States of America: Wynder, Bross, Cornfield and O'Donnell (1956) reported a study of the role of environmental factors in the development of lung cancer in 196 women ; Haenszel, Shimkin and Mantel (1958) published a retrospective investigation of 158 women; and Boucot and Percy (1960) reported a further series of 102 cases. A useful review of lung cancer in women was given in the Lancet (1957), and the sex ratio problem was also reviewed by Kirchoff and Rigdon (1959). Reports from other countries include those of Sträuli (1958) and of Giova and Marinelli (1959). In view of the comparatively small total number of female cases studied, it was considered worthwhile to investigate a further series in order to augment statistical information.

The present series is composed of 100 consecutive cases from which histological material was examined in the pathology department of this hospital, covering a period between the years 1948 and 1962. Post-mortem examinations were carried out on 43 cases, three of which had had previous pneumonectomies and one a previous lobectomy. The other 57 were collected from the routine surgical histology; this comprised 30 bronchoscopic biopsies, 14 pneumonectomy specimens, nine lobectomy specimens, two thoracotomy biopsies, and two lymph node biopsies.

\section{AGE INCIDENCE}

The average age of the patients in this series at the time of diagnosis was 58 (to the nearest whole number), the mean figure for the necropsy cases being 60 and that for the surgical cases 56 years.
The oldest patient was 75 , the youngest 12 , and 69. of the 100 cases were aged 55 years or over.

These figures show a somewhat higher average age incidence than for bronchogenic carcinoma in general, Willis (1960) having given the mean age of various series as ranging between 45 and 55. Spencer (1962) referred to the later age of the peak incidence of lung cancer in women as having beene a universally noted feature, and gave a diagram to show that the peak incidence in women occurreb approximately 10 years later than in men.

\section{SMOKING HABITS}

It is not usually possible to obtain very detaileक information in a retrospective survey, and only broad categories of smoking habits can be given here. Out of the 100 cases, 14 were classed as heavy smokers ( 20 or more cigarettes per day for many years), 24 as medium smokers (10 or more. cigarettes per day at some time), 10 as light smokers (less than 10 cigarettes per day at some time), three as very occasional smokers, and 29 as $^{x}$ non-smokers. In three cases the only information was that they 'used to smoke', and in 17 cases no. information about smoking was obtainable.

Todd (1957, quoted by Hammond, 1958) estimated that $41.6 \%$ of women aged 16 and over were smoking cigarettes in the United Kingdom? in 1956, and that $5 \%$ of women smokers smokedE. more than 20 cigarettes a day. In a series of 108 women with lung cancer reported by Doll and Hill (1952), $11.1 \%$ had been smoking 25 or more cigarettes a day, compared with $0.9 \%$ of controls, and $37 \%$ were non-smokers, compared with $54.6 \%$ of controls; and in the U.S.A. Wynder et alo (1956) and Haenszel, Shimkin, and Mantel (1958) found a significant association between cigarette-smoking and lung cancer in their female series The figures of the present series also lend suppor to this association.

Smoking habits in relation to previous respira tory disease and to histological type are referred to below. 


\section{PAST HISTORY OF RESPIRATORY DISEASE}

Records of a past history of respiratory disease or symptoms were found in 47 patients, some of whom had had more than one malady. Symptoms or illnesses immediately preceding and referable to the development of bronchogenic carcinoma have not been included. There were 27 cases of 'chronic cough' (including 'smoker's cough' (3), 'winter cough' (5), and 'chronic bronchitis' (8) ), 11 cases of pneumonia, eight of pleurisy or empyema, three of sinusitis, two of pulmonary tuberculosis, two of asthma, and one of 'lung congestion'.

The figures here are too small to be of significance in themselves, but they may be of use in conjunction with further studies. Opinions differ on the role of preceding respiratory disease in relation to cancer. Willis (1960), for example, stated that there was no satisfactory evidence that any of the common infections of the bronchi or lungs predisposed to carcinoma. Passey (1962), on the other hand, suggested that one factor affecting the high male/female ratio was the relative sex incidence of chronic respiratory disease, and he concluded that chronic respiratory disease-in particular, chronic bronchitis-might in part determine differences in the lung-cancer incidence in different countries.

Wynder et al. (1956) found that previous lung complaints in women were more frequently reported by patients with epidermoid carcinoma than by those with adenocarcinoma, the difference having been due mainly to the greater frequency of chronic cough in the former group and in cigarette smokers.

In the present series the heavy and medium smokers, as might be expected, were also found to have a higher incidence of 'chronic cough' (including 'smoker's cough', 'winter cough', and 'chronic bronchitis') than the non-smokers and remainder ; but there was no appreciable difference between the two groups with regard to a past history of respiratory disease other than 'chronic cough' (Table I).

TABLE I

MOKING HABITS AND PAST HISTORY OF RESPIRATORY DISEASE

\begin{tabular}{|c|c|c|c|c|}
\hline & \multirow[b]{2}{*}{$\begin{array}{l}\text { Total } \\
\text { No. of } \\
\text { Cases }\end{array}$} & \multicolumn{3}{|c|}{ No. of Cases with a Past History of } \\
\hline & & $\begin{array}{c}\text { Respira- } \\
\text { tory } \\
\text { Disease }\end{array}$ & $\begin{array}{l}\text { 'Chronic } \\
\text { Cough' }\end{array}$ & $\begin{array}{c}\text { Respiratory } \\
\text { Disease other } \\
\text { than 'Chronic } \\
\text { Cough' }\end{array}$ \\
\hline $\begin{array}{l}\text { Heavy and } \\
\text { medium smokers } \\
\text { Non-smokers and } \\
\text { remainder } \quad . .\end{array}$ & $\begin{array}{l}38(100)^{1} \\
62(100)\end{array}$ & $\begin{array}{l}25(66) \\
22(35)\end{array}$ & $\begin{array}{l}16(42) \\
11(18)\end{array}$ & $\begin{array}{r}9(24) \\
14(23)\end{array}$ \\
\hline
\end{tabular}

1 The percentages, in parentheses, are given to the nearest whole number.
SITE OF TUMOUR

The right lung was affected in 57 cases, the left lung in 42 , and both lungs diffusely in one case. The lobar distribution of 72 cases was right upper (20), right middle (5), right lower (15), left upper (15), and left lower (17).

As regards the part of the lung affected, 24 tumours appeared to arise in the main lung bronchi, 36 in the main lobar bronchi, 23 in segmental bronchi, and eight in the lung periphery; nine were unclassified. Thus there were 60 tumours apparently arising from the larger bronchi and 31 situated more peripherally.

Most large series of lung cancer cases, including both sexes, have shown a slight preponderance of growths in the right lung (Spencer, 1962), as might be anticipated from the relative sizes of the two lungs (Willis, 1960), and the present series of female cases is no exception in this respect. The lobar distribution also shows no striking differences from other series, the largest number of growths having been in the right upper lobe. Comparisons with regard to the part of the lung affected are more difficult because of the different methods of anatomical grouping used and the differences in distribution figures based on surgical resected specimens and post-mortem material. Figures based on surgical specimens give a lower figure for peripheral growths (Spencer, 1962). Walter and Pryce (1955b), however, found about one half of the tumours in an unselected, consecutive surgical series to be peripheral but quoted several other authors to show that the accepted teaching had been that the majority of tumours arose in the major bronchi near the hilum. Certainly in the present series there was a preponderance of more centrally-placed growths.

\section{HISTOLOGICAL TYPE}

The tumours were classified according to their predominant structure, the resulting figures being:

\begin{tabular}{lc} 
Oat-cell carcinoma & 39 \\
Undifferentiated carcinoma & 23 \\
Squamous-cell carcinoma & 21 \\
Adenocarcinoma & 17 \\
\cline { 2 - 2 } & 100 cases
\end{tabular}

If oat-cell carcinoma is regarded as a variety of undifferentiated structure, then these two groups together accounted for $62 \%$ of cases.

There has been a marked lack of uniformity in the classification of histological types of lung cancer, one of the difficulties having been the 
frequency of structural variants in individual tumours, and another, the interpretation of histological appearances (Walter and Pryce, 1955a). Willis (1960) questioned the validity and value of the histological subdivisions and stated that they were necessarily arbitrary. There have also been differences between the proportions of histological types in surgical and post-mortem series; Boucot and Percy (1960) wrote that all surgical series, predominantly men, reported a preponderance of squamous-cell carcinoma.

With regard to other reported female series, Wynder et al. (1956) found $42 \%$ of their cases to be adenocarcinoma, $32 \%$ epidermoid, and $18 \%$ anaplastic; in reviewing other studies of lung cancer in women, they also found a greater proportion of adenocarcinomas than in similar studies of male cases, quoting recent series as having shown about $50 \%$ of cases to be of the glandular type in contrast to $5 \%$ to $20 \%$ reported by different investigators among men. Boucot and Percy (1960), however, found the proportion of squamous cell carcinoma, adenocarcinoma, and undifferentiated carcinoma to be roughly the same in their female series; and Nicholson, Fox and Bryce (1957), in a mixed surgical series from Manchester, found an approximately equal incidence of adenocarcinoma between the two sexes but a much larger proportion of oat-cell tumours in women. The present series is of interest in having shown a fairly low proportion of adenocarcinomas and a high combined incidence of oatcell and undifferentiated tumours.

The histological types were also correlated with age incidence, smoking habits, and tumour location (Table II).

T A B L E I I

HISTOLOGICAL TYPES IN REI ATION TO AGE INCIDENCE, SMOKING HABITS, AND TUMOUR LOCATION

\begin{tabular}{|c|c|c|c|c|c|}
\hline & \multicolumn{4}{|c|}{ Histological Type } & \multirow[b]{2}{*}{ Total } \\
\hline & $\begin{array}{l}\text { Oat- } \\
\text { cell }\end{array}$ & $\begin{array}{c}\text { Undifferen- } \\
\text { tiated }\end{array}$ & Squamous & $\begin{array}{c}\text { Adeno- } \\
\text { carcinoma }\end{array}$ & \\
\hline $\begin{array}{l}\text { Under } 55 \text { years } \\
55 \text { years and } \\
\text { over }\end{array}$ & $\begin{array}{l}11(36) \\
28(41)\end{array}$ & $\begin{array}{l}10(32) \\
13(19)\end{array}$ & $\begin{array}{c}5(16) \\
16(23)\end{array}$ & $\begin{array}{r}5(16) \\
12(17)\end{array}$ & $\begin{array}{l}31(100) \\
69(100)\end{array}$ \\
\hline $\begin{array}{l}\text { Heavy and } \\
\text { medium } \\
\text { smokers ... } \\
\text { Non-smokers } \\
\text { and } \\
\text { remainder }\end{array}$ & $\begin{array}{l}18(47) \\
21(34)\end{array}$ & $\begin{array}{l}9(24) \\
14(23)\end{array}$ & $\begin{array}{l}9(24) \\
12(19)\end{array}$ & $\begin{array}{c}2(5) \\
15(24)\end{array}$ & $\begin{array}{l}38(100) \\
62 \quad 100)\end{array}$ \\
\hline $\begin{array}{l}\text { Tumours aris- } \\
\text { ing from } \\
\text { larger bronchi } \\
\text { More peri- } \\
\text { pheral } \\
\text { tumours ... }\end{array}$ & $\begin{array}{l}26(43) \\
8(26)\end{array}$ & $18,30)$ & $\begin{array}{l}11(18) \\
10(32)\end{array}$ & $\begin{array}{l}5(8) \\
9(29)\end{array}$ & $\begin{array}{l}60(100) \\
31(100)\end{array}$ \\
\hline
\end{tabular}

The percentages, in parentheses, are given to the nearest whole number.
As regards the age incidence, it was found that there was a higher proportion of undifferentiated? tumours below the age of 55 than above, with less $\frac{\overline{0}}{\bar{s}}$ marked variations in the other types. Wynder et al. (1956) found that women with epidermoid $\stackrel{\circ}{\circ}$ cancer were somewhat younger than those withes adenocarcinoma, and that patients with anaplastic $\overrightarrow{0}$ and undifferentiated carcinoma seemed to beintermediate in age.

The correlation with smoking habits showed? that the heavy and medium smokers, when com-x pared as one group with the non-smokers and $\overrightarrow{0}$ remainder as another, showed a considerablye higher proportion of oat-cell tumours, a slightly $y_{\omega}^{\omega}$ higher one of squamous cell growths, and a much ${ }^{\infty}$ lower one of adenocarcinomas. Haenszel, Shimkino and Mantel (1958) stated that their findings agreed with three other investigations of lung cancer in $\subseteq$ women in pinpointing a major effect associated with a history of smoking cigarettes, particularlyc for neoplasms of the epidermoid and undiffer $\rightarrow$ entiated histological types. Doll, Hill and kirey-O berg (195\%) tound a close relationship in men between the daily amount smoked and the development of squamous, large-cell, and small-@ cell carcinomas (including oat-cell and anaplastic carcinomas), but only a slight, if any, relationship $\overrightarrow{\vec{B}}$ with the development of other histological types. $\frac{3}{3}$ They found it was impossible, however, to decide whether the same distinction held for women owing to the small number of cases.

With regard to the relationship between the histological type and tumour location, when then 60 tumours arising from the larger bronchi were compared with the 31 situated more peripherally 3 . the central tumours were found to have highero proportions of oat-cell and undifferentiated3 structure, whereas there was a much higher per-o centage of adenocarcinomas in the peripheral group. The latter finding is in line with theo generally accepted view that the majority of glandular carcinomas in both sexes occur in theos periphery of the lung (Spencer, 1962), but moren information is needed before any trends can beN discerned as to the location of the other histologi- $\omega$ cal types of lung cancer in women.

\section{TUMOUR SPREAD}

Neoplastic involvement of other organs could only be determined in the 43 cases which came to̊ necropsy, and the organs found to be most fre- $\frac{\mathbb{D}}{2}$ quently affected are shown in Table III.

Other structures less frequently affected were the chest wall, thyroid, and kidneys ( 5 cases each)응 
TABLE III

TUMOUR SPREAD (PRINCIPAL ORGANS) IN 43 NECROPSY CASES

\begin{tabular}{|c|c|c|c|c|c|}
\hline \multicolumn{4}{|c|}{ Organ Involved } & No. of Cases & Percentage $^{1}$ \\
\hline \multicolumn{4}{|c|}{ Hilar or mediastinal lymph nodes } & \multirow{9}{*}{$\begin{array}{r}34 \\
19 \\
18 \\
17 \\
16 \\
14 \\
12 \\
7 \\
7 \\
7\end{array}$} & \multirow{9}{*}{$\begin{array}{l}79 \\
44 \\
42 \\
40 \\
37 \\
33 \\
28 \\
16 \\
16 \\
16\end{array}$} \\
\hline Liver $\quad$. & $\ldots$ & $\ldots$ & & & \\
\hline Skeleton $\quad \ldots$ & & .. & .. & & \\
\hline Abdominal lyr & nod & .. & . & & \\
\hline Adrenal gland & & & $\ldots$ & & \\
\hline Cervical lymp & odes & & . & & \\
\hline $\begin{array}{l}\text { Pleurae } \\
\text { Lungs (separa }\end{array}$ & $\ddot{n}$ & & $\cdots$ & & \\
\hline Pericardium & epos & . & $\because$ & & \\
\hline Brain .. & . & . & . & & \\
\hline
\end{tabular}

1 To the nearest who'e rumber

the heart, oesophagus, and pancreas (4 cases each), the spleen ( 3 cases), and the peritoneum, meninges, and uterus ( 2 cases each). Several other sitesdiaphragm, skin, breast, tongue, stomach, anus, and spinal cord-were involved in single instances. The central nervous system may well have been involved more frequently as the brain was not examined in 17 cases. The pattern of spread shown here is very similar to that of bronchogenic carcinoma in general (Willis, 1960 ; Spencer, 1962), except perhaps for a rather higher incidence of skeletal involvement and a lower incidence of renal metastases.

\section{SURVIVAL AFTER FIRST SYMPTOMS OR DIAGNOSIS}

Although the time of onset of lung cancer cannot be determined with precision, an attempt was made to calculate the approximate length of survival from the onset of symptoms related to the disease or from the time of diagnosis, the latter being appropriate to tumours found by mass miniature radiography. The cases were grouped according to whether or not surgical resection had been carried out. The average length of survival of 69 non-resection cases was found to be approximately eight months, whereas 22 resection cases had an average survival of approximately 22 months. There were five cases in which length of survival could not be determined, and four patients are still alive at the time of writing, having survived more than eight, eight, five, and two years, respectively.

In the series reported by Boucot and Percy (1960), $77 \%$ of the women died within one year of the date of tissue diagnosis, and there was an overall five-year survival rate of only $3 \%$, which was stated to be somewhat worse than the overall survival figures reported in the literature. Bignall and Moon (1955), however, in a study of the duration of life after lung resection for bronchial carcinoma, found that the prognosis was better in women than in men, but stated that it was impossible to be sure that the differences in mortality were due only to sex differences in the behaviour of the tumour. Ederer and Mersheimer (1962) also found that the five-year survival rate for women with lung cancer treated surgically was greater than that for men.

Close comparisons of survival rates are obviously difficult on account of the many variable factors involved, and it will probably not be possible to draw any firm conclusions until figures for a much larger number of female cases are published.

\section{OTHER FACTORS INVESTIGATED BUT OF DOUBTFUL SIGNIFICANCE}

Eighty-five of the 100 cases were known to have been married and 61 to have had one or more pregnancies. One woman, aged 47 , with a diffuse adenocarcinoma had taken stilboestrol indiscriminately for the menopause a year previously. This is of interest in connexion with the possible association of hyperoestrinism with adenocarcinoma (Sommers, 1958).

As regards the area of residence, 62 patients had home addresses in the London postal area, 15 in towns with a population of 50,000 or more, and 23 in towns or places with a population of less than 50,000 .

Nothing significant was found from occupational histories, but of some interest were three non-smoking housewives who came from small country towns; one had had a dry cough for 20 to 30 years, the other had suffered from chronic asthma and catarrh, but the third had had no past history of respiratory disease ; all three had oatcell carcinomas. There were also two very light smokers from small country towns, one a landscape-gardener who had a squamous-cell tumour, and the other a housewife and farm worker who had an oat-cell tumour.

Nothing of interest was learnt from family histories, and there was no unusual distribution of blood groups in 59 cases where these were known.

\section{SUMMARY}

One hundred consecutive cases of lung cancer in women, which had been examined histologically, were studied with a view to augmenting statistical information as the unequal sex incidence of the disease constitutes an obvious line of enquiry into aetiology. 
The average age of the patients in this series was 58 years, being somewhat higher than for bronchogenic carcinoma in general. The figures for smoking habits lend support to the association between cigarette-smoking and lung cancer. Records of a past history of respiratory disease or symptoms were found in 47 cases. The anatomical distribution of the tumours showed no unusual pattern, higher relative frequencies having been found in the right lung, the right upper lobe, and in the larger bronchi. There was a high combined incidence $(62 \%)$ of oat-cell and undifferentiated tumours, with a lower incidence $(17 \%)$ of adenocarcinomas. Undifferentiated tumours were more common below the age of 55 ; heavy and medium smokers had a higher proportion of oat-cell tumours and fewer adenocarcinomas; and there was a higher incidence of adenocarcinomas among the more peripheral tumours. The pattern of tumour spread in 43 necropsy cases was similar to that of bronchogenic carcinoma in general, except for a somewhat higher incidence of skeletal involvement and a rather lower incidence of renal metastases. The average length of survival of 69 non-resection cases was approximately eight months, whereas 22 resection cases had an average survival of approximately 22 months.

Several other factors, such as marital state, parity, place of residence, occupation, family history, and blood groups were considered but yielded nothing of obvious significance.
The literature has been briefly reviewed and $\overrightarrow{\bar{s}}$ comparisons have been made with some of the findings of the present study. It is evident that more statistical information is needed on many aspects of lung cancer in women.

\section{REFERENCES}

Bignall, J. R., and Moon, A. J. (1955). Survival after lung resection for bronchial carcinoma. Thorax, 10, 183.

Boucot, Katharine R., and Percy, Helen (1960). Lung cancer i⿹ women. Dis. Chest, $38,587$. Doll, R., and Hili, A. B. (1952). A study of the aetiology of carcinom?
of the lung. Brit. med. J., 2, 1271 . and Kreyberg, L. (1957). The significance of cell type ito relation to the aetiology of lung cancer. Brit. J. Cancer, 11, 43

Ederer, F., and Mersheimer, W. L. (1962). Sex differences in the survival of lung cancer patients. Cancer, 15, 425. Giova, C., and Marinelli, N. (1959). Carcinomi bronco-polmonar $\mathscr{W}_{0}$
primitivi delle donne. Rass. int. Clin. Ter., 39, 703.

Haenszel, W. Shimkin, M. B., and Mantel, N. (1958). A retrospectiv study of lung cancer in women. $J$ nat. Cancer Inst $21,825$.

Hammond, E. C. (1958). Lung cancer death rates in England anctWales compared with those in the U.S.A. Brit. med. J., 2, 649c

Kirchoff, Helen, and Rigdon, R. H. (1959). Cancer of the lung-the sex ratio; a review of the problem. Tex. Rep. Biol. Med., 17, 29

Lancet (leading article) (1957). Lung cancer in women. Lancet, 1, 571

Nicholson, W. F., Fox, M., and Bryce, A. G. (1957). Review of $91 \circlearrowright$ cases of bror.chial carcinoma with results of treatment. Ibid., 10

Passey, R. D. (1962). Some problems of lung cancer. Ibid., 2, 107 Sommers, S. C. (1958). Host factors in fatal human lung cancer Arch. Path., 65, 104.

Spencer, H. (1962). Pathology of the Lung, ch. 19. Pergamon Press Oxford.

Sträuli, P. (1958). Der Lungenkrebs der Frau. Schweiz. med. Wschr.

Walter, J. B., and Pryce, D. M. (1955a). The histology of lung cancer요 Thorax, 10, 107.

- $1955 \mathrm{~b})$. The site of origin of lung cancer and its relation to histological type. Ibid., 10, 117.

Willis, R. A. (1960). Pathology of Tumours, 3rd ed., ch. 19. Eutter worth, London.

Wynder, E. L., Bross, I. J., Cornfield, J., and O'Donnell. W. E. (1956) Lung cancer in women: a study of environmental factors. New Engl. J. Med., 255, 1111 . 